\title{
The Nutritional Components of Rice are Closely Related to Grain Quality Traits in Rice
}

Bo Peng (Corresponding Author), Ke-Xin Jin, Dian-Ya Luo, Xia-Yu Tian, Yan-Fang Sun, Xin-Hua Huang, Rui-Hua Pang, Quan-Xiu Wang, Wei Zhou, Hong-Yu Yuan (Corresponding Author)

College of Life Sciences and Institute for Conservation and Utilization of Agro-bioresources in Dabie Mountains, Xinyang Normal University, Xinyang, China

Fang Yang

State Key Laboratory of Hybrid Rice, College of Life Sciences, Wuhan University, Wuhan, China

Juan Peng

Xinyang Station of Plant Protection and Inspection, Xinyang, China

Hui-Long Li, Xiao-Hua Song

Xinyang Academy of Agricultural Science, Xinyang, China

\section{Xin-Xiang A}

Yunnan Provincial Key Lab of Agricultural Biotechnology of Yunnan Academy of Agricultural Sciences \& Scientific Observation Station for Rice Resource of Yunnan, Ministry of Agriculture, Kunming, China

Received: Aug. 30, $2020 \quad$ Accepted: Sep. 28, 2020

doi:10.5296/jbls.v11i2.17809 URL: https://doi.org/10.5296/jbls.v11i2.17809

\begin{abstract}
Starch, protein and lipid are the most important nutrients in rice, and their composition and content in rice grains play a decisive role in the grain quality. Rice quality (including appearance quality, cooking quality, nutrition quality, grinding and processing quality, etc.) is
\end{abstract}


not only affected by the composition of the nutrients in grain of rice, but also by the physical and chemical characteristics and their content in grains, but also vulnerable to external environmental conditions. To clarify the relationship between the main nutrients in rice and their grain quality traits is of great theoretical significance and potential application value for the continuous improvement of rice quality in the future. Therefore, this paper reviewed the effects of starch, protein, lipid and mineral elements in grain of rice and also on quality of trait in rice. It is also discussed the relationship between these nutrients and rice grain quality traits. All of those will provide important information for the quality of grain improvement and breeding of new varieties with high quality in rice.

Keywords: rice; nutrients, grain quality, quality trait

\section{Introduction}

Rice (Oryza sativa L.) is one of the most important food crops in the world, providing about 25 percent of the energy needs of more than 3 billion people in the world. Especially in South-East Asia, rice supplies about $76 \%$ of the energy to its local population. Hence rice is an extremely important source of human energy and nutrients (Kong et al., 2015; Peng et al., 2014). The main nutrients in rice grains are starch, protein and lipids. Most of the nutrients in rice are starch and protein, which weigh more than 90\% of the dry weight (He et al., 2013; Peng et al., 2016). Starch in rice grain includes amylose and amylopectin. Their structural composition and relative content has important influence on many qualities of rice. Rice contains no more than $16 \%$ of its dry weight (Peng et al., 2014; Juliano et al., 1972), but it provides $15 \%$ of the world's edible protein (He et al., 2013), As a major source of protein (Peng et al., 2014; raubenheimer et al., 2016). Meanwhile, grain protein content in rice grian is an important factor to determine its nutritional quality. Lipids, including fats and phospholipids, are an important nutrient in rice seeds, mainly distributed in rice seed embryo and endosperm outside the aleurone layer, and a complex is formed between lipids and amylose in rice seeds (Xu et al., 2015; Goufo et al., 2014). Thus, the composition and content of the major nutrients such as starch, protein and lipid have important effects on rice quality.

Rice quality character is a very complex quantitative character, mainly composed of appearance quality, cooking quality, nutritional quality, grinding and processing quality (Yun et al., 2016; Peng et al., 2014). The appearance quality of rice is mainly determined by chalkiness, grain shape (grain size or shape) and transparency (translucency) (Zhang, 2007; Wan et al., 2008). The grain type is mainly expressed by the length, width and aspect ratio of the grain. The chalkiness trait is divided into dorsal white (white back), heart white (white core) and abdominal white (white belly) according to its occurrence. The transparency of the rice is divided into opaque, translucent and transparent, reflects the brightness of whole rice under light penetration. Rice cooking quality refers to the sensory and physicochemical properties of rice during cooking. The physical and chemical indexes: amylose content (AC), gel consistency (GC) and gelatinization temperature (GT) (Wang et al., 2011). The grinding quality of rice is mainly measured by three indexes: brown rice rate, milled rice rate and whole milled rice rate (Zhang et al., 2016). Among them, the whole rice rate is an important factor to evaluate the quality of rice grinding ( $\mathrm{Li}$ et al., 2016). The nutritional quality of rice 
grain depends mainly on the extent and relative content of nutrients in the grains, nutrients in rice grain mainly include crude protein (crude protein content, CPC), fats, starch, amino acids and vitamins and other trace elements (Yu et al., 2006; Yoon et al., 2012). In addition to being influenced by the composition of nutrients, physical and chemical properties and their contents in seed grains, and grain quality traits (Table 1), are also vulnerable to external environmental conditions. For example, if the temperature of rice grain filling period is high, it is easy to form chalkiness characters in seed endosperm. Simultaneously, the appearance quality, cooking quality and food quality of rice were also affected.

Over the past decade, significant progress has been made in the field of the genetic aspects of major nutrients in rice (Zhou et al., 2017; Bhullar et al., 2013). A large number of genes was isolated and cloned, which are involved in the regulation of the synthesis, metabolism and degradation of major nutrients such as starch, storage proteins, lipid substances and vitamins in rice (Yu and Wang, 2016; Wang et al., 2013). The main nutrients in rice seeds are closely related to the grain quality traits of rice. Therefore, it is of great theoretical significance and potential application value to clarify the relationship between the main nutrients such as starch, protein, lipids and mineral elements in rice grain and their grain quality traits in the future. This paper focuses on the analysis of the effects of the main nutrients in rice, including starch, protein, lipids and mineral elements, on the main traits of grain quality in rice, which will provide important reference for the improvement of grain quality and the breeding of new rice varieties with high quality.

Table 1. A selection of relations between physical-chemical characteristics of raw rice and the sensory quality of cooked rice (Mestres et al., 2019)

\begin{tabular}{cll}
\hline $\begin{array}{c}\text { Physical-che } \\
\text { mical } \\
\text { characteristics } \\
\text { of } \\
\text { raw rice }\end{array}$ & $\begin{array}{l}\text { Sensory attribute } \\
\text { of cooked rice }\end{array}$ & $\begin{array}{l}\text { Selected } \\
\text { references }\end{array}$ \\
\hline & •Positive correlation with firmness/hardness & Champagne et \\
& Negative correlation with stickines & al. (2004), \\
& & Juliano et al. \\
& & $(1981)$, \\
& & $\begin{array}{l}\text { Mestres et al. } \\
(2011)\end{array}$ \\
& & Lyon et al. \\
Amylose content & texture attributes & (1999) \\
& $\bullet$ Negative correlation with & Srisawasand \\
& acceptability & Jindal (2007) \\
& $\bullet$ Reduces aroma and sweetness and & $\begin{array}{l}\text { Bett-Garber et } \\
\text { al. (2013) }\end{array}$ \\
& increases bitterness of brown rice & Bett-Garber et \\
& $\bullet$ Waxy milled rice is more aromatic & al. (2007)
\end{tabular}


-Negative correlation with"grain”aroma attribute for cooked milled rice

-Hot-water-insoluble amylose is negatively correlated with stickiness and tenderness

\author{
Amylose \\ characteristics
}

Amylopectin structure

Starch gelatinization Temperature

Protein content

- Proportion of long-chain amylose is positively correlated with sensorial hardness

- Firmness increases with the forma-tion of amylose-lipid complex II during parboiling Long-chain amylopectin proportion is positively correlated with the hardness score and negatively with the stickiness score for cooked parboiled rice and for cooked milled rice

-Cooking time increases with an in-crease in the gelatinization temperature

-Hardness score at the core of the grain increases with an increase in The gelatinization temperature

Positive correlation with stickiness and slickness Negative correlation with hardness

(n)

Rice grain
structure

\section{Champagne et} al. (2004)

Bhattacharya et al. (1978),

Sowbhagya et

al. (1987)

Li et al. (2016)

Rousset et al.

(1999)

Li et al. (2016),

Ong and

Blanshard

(1995)

Fitzgerald et al. (2009),

Juliano and

Perez (1983)

Mestres et al.

(2011)

Champagne et

al. (2004,

2009), Mestres

et al.

(2011)

-The cooking time increases with the thickness

Vidal et al. of the grain

(2007)

Matsue et al.

(2001)

Kim et al. (2000)

\section{The Relationship Between Rice Starch and Grain Quality Traits}

Starch is the main component in rice endosperm, and it accounts for about $77-78 \%$ of the milled rice with water content of $14 \%$. Therefore, many scholars believed that the composition, physical and chemical properties and structure of starch determined the eating quality of rice (Mo, 1993). Physicochemical properties of starch are important factors affecting the eating quality of rice (Bergman et al., 2004; Rameshet et al., 2000). Rice with high amylose content tends to have higher hardness and lower viscosity. Remarkably, there is no significant correlation in some cases (Rousset et al., 1999), lack of significant correlation 
may be associated with specific rice samples. Long-chain amylopectin makes cooked rice harder, with a lower viscosity (Ong and Blanshard, 1995). The gelatinization temperature is an important index to evaluate the cooking quality of rice. It reflects the nature of starch, have an important effect on the cooking performance and grain quality of rice. The higher the gelatinization temperature, cooking rice takes longer (Fitzgerald et al., 2009; Juliano and Perez, 1983). Interestingly, there were some correlations between grain hardness and gelatinization temperature (Mestres et al., 2011). A study of 46 samples found a significant positive correlation between starch gelatinization temperature and sensory score of core hardness of rice grains. The morphology of rice starch granules is closely related to its grain quality. Rice varieties with good quality, its starch granules are small, polyhedral, arranged neatly and close. Rice varieties with poor quality, the size of starch granules in the chalkiness part of grain was uneven, and the edges of the polyhedron were not obvious, rough surface, arranged loosely and irregularly (Figure 1) (Ji et al., 1998; Peng et al., 2018). Starch in rice is mainly composed of amylose and amylopectin (Yang, 2003; Jin, 2008), their relative content and physicochemical properties have important effects on grain quality traits in rice.

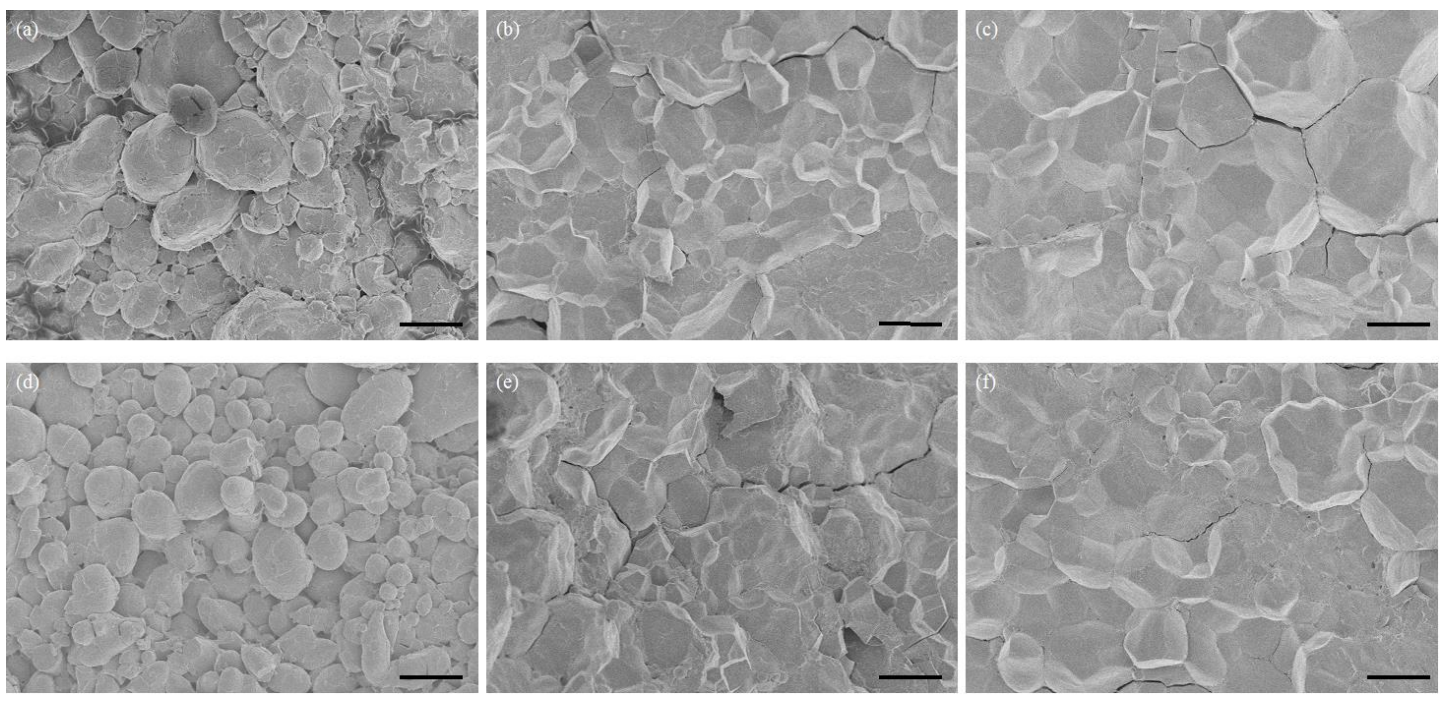

Figure 1. Scanning electron microscopic observation on starch granules in endosperm cells of the chalky and non-chalky grains (Peng et al., 2018)

a, d: the starch grains in the chalky rice; b, e: the starch grains in the transparent parts of rice; $\mathrm{c}, \mathrm{f}$ : the starch grains in the non-chalky rice; $\mathrm{Bar}=8 \mu \mathrm{m}$.

\subsection{The Relationship Between Amylose and Grain Quality Traits in Rice}

Amylose is a linear glucose polymer that naturally curls to form a natural spiral structure. The crystal structure of rice after heating and gelatinization is very firm. The thermal stability is strong, and it is not easy to be hydrolyzed by amylase, so amylose has a fiber-like property. Rice with high amylose content can not only improve the intestinal function of human body as dietary fiber in food, but also have low raw sugar index. The long-term consumption can effectively reduce blood sugar in human body and has a good health care effect (Champagne et al., 1996), which is also one of the main traits in the process of rice quality selection (Figure 2). 
Some studies have found the significant differences between the main quality traits and rice texture indexes in four rice lines with different amylose content (Cai et al., 2005). The decrease of amylose content in rice grain makes the consistency of starch soft and the content of crude protein decrease. Too low amylose content will cause the appearance of rice grain to show waxy character. Characteristics in rice RVA spectrum and rice texture are obviously controlled by amylose content in rice, and amylose content in rice obviously affects the change of viscosity during gelatinization. The rice varieties with higher amylose in rice have higher reduction value, recovery value, hot pulp viscosity, final viscosity, and the rice flour made by processing has higher retrogradation. Of course, they are difficult to paste. By contrast, rice varieties with lower amylose content in rice have lower reduction value, recovery value, hot pulp viscosity, final viscosity, and the retrogradation of rice flour in cooling process is smaller, its rice texture is more sticky, chewing without slag feeling, elastic (Cai et al., 2005). Interestingly, the relationship between amylose content and the highest viscosity and disintegration value in rice is not a simple linear relationship. When amylose content in rice grain is low, the highest viscosity and disintegration value increase with the amylose content. When the amylose content in rice grain is higher than a certain value, the increase of amylose in rice will decrease the highest viscosity and disintegration value. But there are also some studies results showed that rice varieties with the same amylose content may also have a large difference in rice texture, which may be related to the chain length of amylose and the distribution of its branches (Wang, 2016). Generally speaking, the more long chains of starch in rice, the harder the texture of rice.

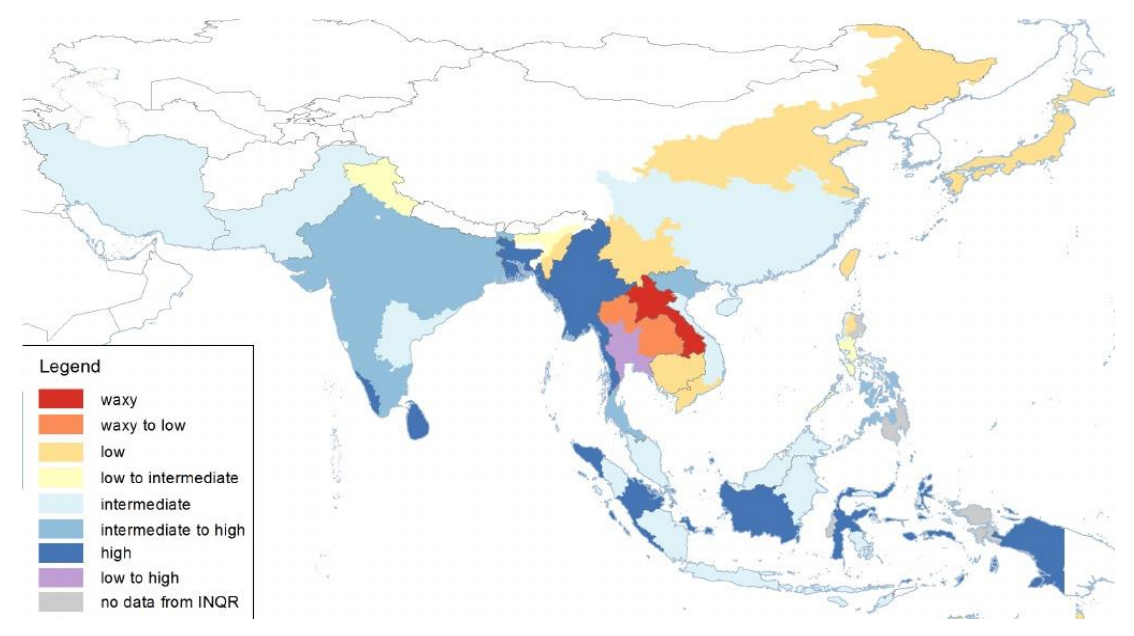

Figure 2. Regional differences in amylose content among the three most popular rice varieties in Asia (data from NQR representatives from each region) (Calingacion et al.,

2014)

Furthermore, the amylose content of grain significantly affect the genetic correlation between brown rice weight and appearance quality traits, and also affect the correlation of paired traits in different genetic systems such as endosperm, cytoplasm and maternal plant in rice (Ge et al., 2007). The processing quality, appearance quality, cooking quality and RVA parameters of 135 japonica rice germplasm resources were analyzed, and the results showed that amylose content was positively correlated with chalkiness rate, hot pulp viscosity, cold pulp viscosity 
and recovery value in rice (Hu et al., 2020). Therefore, the amylose structure and its content in grains have important influence on the grain quality traits of rice.

\subsection{The Relationship Between Amylopectin and Grain Quality Traits in Rice}

Starch is divided into amylose and amylopectin in rice, and the difference of fine structure of amylopectin is an important factor leading to the difference of grain quality between amylose content (AC) similar varieties (Kusano et al., 2015; Peng et al., 2014; Zhang et al., 2016). Fine structure of amylopectin, including chain length and chain length distribution, average chain length (CL), average exterior chain length (ECL), average internal chain length (ICL), A: B values and other parameters (Yao et al., 2004). The chain length distribution of amylopectin could be used to describe the branching structure of amylopectin. According to the degree of polymerization (DP) of amylopectin branched chain size, the chain length can be divided into: A chain (DP 6.12), Bl chain (DP 13.24), B2 chain (DP25.36) and B3 chain $(\mathrm{DP} \geq 37$ ). Starch chain length and amylopectin length, medium, short chain ratio was different, could make the same AC variety are different gelatinization temperature and glue consistency (Hu et al., 2007). The proportion of amylopectin in different chain length range was mainly related to starch gelatinization temperature, but not closely related to the gum consistency and RVA paste characteristics of starch (He et al., 2010). The short chains with degree of polymerization (DP) of 6-9 caused a decrease in gelatinization temperature, while chains with DP of 12-22 caused an increase in the onset gelatinization temperature (To); amylopectin with DP values of 6-9 and DP > 25 decreased the end gelatinization temperature (Te) and enthalpy of gelatinization $(\Delta \mathrm{H})$ of amylopectin (Vandeputte et al., 2004). Amylopectin structure has a great influence on the pasting properties and gelatinization temperature of starch RVA. Rice starch RVA with low average chain length, average outer chain length and high A: B value had better pasting properties and lower gelatinization temperature (Zhou et al., 2018). At the same time, amylopectin was the main factor formed the shape and structure of starch granules (Nakamura et al., 2002). This is also the main reason for the difference in cooking quality of rice varieties similar to AC. The amylopectin branching structure had a certain correlation with the physicochemical properties of rice, especially the A-chain of amylopectin was closely related to the highest viscosity of RVA, disintegration value and starch crystal formation (Cheethamnw et al., 1998; Li et al., 2010). Through the studied on the physical and chemical properties, cooking and starch molecular structure of different of 20 rice varieties from China and Japan. Analyzing their correlation with the eating quality, it was found that the amount of real amylose content in rice was not the main factor determining the taste of rice (Jin et al., 2010). Rice varieties with better taste had higher amylopectin content and lower contents of intermediate components and amylose. The chain length structure of the starch and its components was the key factors determining the eating quality of rice. Among them, the content of amylopectin long chain plays a decisive role in the eating quality of rice. The higher the content of amylopectin long chain, the stronger the force between starch crystals. At the same time, the long chain distributed outside the starch granules is easy to bind with non-starch components, which affects the water absorption of the rice during cooking. The higher the content of short chain, the stronger the internal force of starch crystals, and the better the elasticity of rice grain after cooking. 


\section{The Relationship Between Protein and Quality Traits in Rice}

\subsection{Grain Protein Composition in Rice}

There are many kinds of proteins in rice grain, which can be divided into storage proteins, structural proteins and protective proteins according to their functions (Shewry et al., 2002). Although the content of structural protein is very small, there are many kinds of structural protein in rice grain (Tian et al., 2014). The protein in rice grain usually refers to storage protein. Compared with the other kinds of proteins, the content of storage proteins is higher. More than $90 \%$ of the dry weight of rice grain is composed of stored starch and protein. Protein content in rice embryo is the highest, ranging from $16.8 \%$ to $24.1 \%$. The protein content in brown rice and milled rice varies from $5.1 \%$ to $15.4 \%$ and from $4.5 \%$ to $14.3 \%$, respectively (Tian et al., 2009; Wang et al., 2009). According to the dissolution of stored proteins in rice grain and the different separation methods, stored proteins can be divided into four categories: water-soluble protein, called albumin; dilute salt solution-soluble protein is called globulin; protein that can be dissolved in a mixture of alcohol and water is called prolamin; and protein that can be dissolved in a dilute acid or alkali is called glutenin (Jiao et al., 2008; He et al., 2013). The storage proteins in rice endosperm are mainly glutenin and prolamin, among which glutenin is the most digestible protein, accounting for about $80 \%$ of the protein content in grain endosperm (Wang et al., 2009). The content of prolamin is about $20 \%$ (Kawakatsu et al., 2010; He et al., 2013). The contents of albumin and globulin accounted for about $5 \%$ and $10 \%$ of the total protein content in rice grain, respectively (Krishnan et al., 1986; Shewry et al., 2002; Peng et al., 2014). Overall, the protein content in rice grain ranged from $4.3 \%$ to $19.3 \%$ (Lu et al., 2009; Zhou et al., 2009; Shewry, 2007; Ye et al., 2010), providing about $15 \%$ of the world's population with a source of food protein (He et al., 2013). The balance of endosperm protein content and essential amino acid content in rice grain is one of the two of most important factors determining the nutritional quality of rice (Duan et al., 2005; Peng et al., 2014). Amino acid content in rice grain is relatively balanced with other crops, such as wheat, maize, etc. Therefore, the composition and relative content of the protein in grain play a decisive role in the nutritional quality of rice.

\subsection{The Relationship Between Grain Protein and Appearance Quality in Rice}

The protein content in rice grain is related to its appearance quality. Chalkiness is an optical property formed by the presence of air between starch granule and aleuroplast in endosperm, having an important influence on the grain appearance quality in rice. The chalky index in high chalkiness rice varieties was positively correlated with brown rice rate, milled rice rate, whole milled rice rate, amylose content, taste score value, but negatively correlated with brown rice protein content ( $\mathrm{Li}$ et al., 2015). The total content of the protein and globulin in the chalky part of the same grain was lower than that of the non-chalky part. The albumin content was higher than that of the non-chalky part, and the distribution of glutenin and prolamin content in the chalky and non-chalky parts was not regular, indicating that the difference of protein composition in the chalky and non-chalky parts may be mainly due to globulin and albumin content (Liu et al., 2006). Liu et al (2007) detected and analyzed protein contents in chalky and non-chalky rice showed that the protein content in chalky rice 
was significantly lower than that in non-chalky rice. But in another rice variety, there was no significant difference between them. There was no significant difference in the contents of albumin, globulin and prolamin between chalky rice and non-chalky rice, and the difference of glutenin content between chalky rice and non-chalky rice was the largest. Therefore, the difference of glutenin content may be an important cause of grain chalkiness trait, and then affect the grain appearance quality in rice.

\subsection{The Relationship Between Grain Protein and Cooking Quality of the Rice}

The content of protein and its components in rice grain are different because of its variety, origin, growth and development conditions and processing conditions. In general, the protein content in indica rice was higher than that of japonica rice. The distribution of proteins in the rice grain was not even, the protein content in the aleurone layer of embryo and endosperm surface was higher, and the protein content in grain endosperm was lower (Xie et al., 2003). Protein has a certain effect on cooking quality of rice grain. Previous studies have shown that the effect of protein content on texture properties such as roughness (Champagne et al., 2004, 2009), and adhesion between internal particles (Mestres et al., 2011). In addition, 99 different rice varieties were classified according to their sensory properties, starch and protein content. It was found that the rice varieties with low roughness and high smoothness had lower grain protein content (Bett-Garber et al., 2001). The changes of the protein content and molecular weight in rice during cooking were analyzed synthetically, and the results showed that during rice cooking, proteins combine with other components of rice, instead of simply binding between proteins, which in turn reduces the solubility of proteins. Interestingly, compared with glutelin, the aggregation of prolamin in rice is more obvious, which significantly affects the structure and eating quality of rice (Wang et al., 2015). Although the protein content has a certain degree of influence on the eating quality of rice, different rice varieties have different effects (Xiang et al., 1990). In indica rice, there was a negative correlation between protein content and eating quality. In high-quality rice, protein content and eating quality showed a significant positive effect, and the degree of influence ranked first among all quality traits of rice. All the quality traits of high quality rice varieties have reached a high level. The coordination of these traits may promote the coordination between protein and eating quality, resulting in a positive effect. If the traits are not coordinated, it may weaken the positive effect of protein on eating quality, which may promote the negative effect of protein (Xiang et al., 1990). Therefore, only after the classification of rice samples can the interaction between protein and eating quality be fully reflected.

Rice grain protein was closely related to its cooking quality, and the contents of prolamin and glutenin in different rice varieties (lines) had great influence on the grain quality of rice. However, the contents of albumin and globulin had little effect on the grain quality of rice. The content of glutenin in different rice varieties was negatively correlated with chalkiness rate and chalkiness degree. A significant positive correlation was found between the content of prolamin and the rate of milled rice and whole milled rice (Xu et al., 2015). There was a positive correlation between grain protein and whole milled rate, and negatively correlated with chalkiness and amylose content in rice grain (Jane et al., 1999). Many studies results have showed that there was no significant correlation between total protein content and texture 
characteristics of rice, however, there was a different correlation between protein composition and grain quality (grinding quality, appearance quality and cooking quality), rice texture characteristics and sensory evaluation indexes (Wang et al., 2015). In the grains' protein component, except for prolamin, the other proteins were made up of excellent amino acids, and its nutrition was perfect and had no obvious effect on food eating quality in rice. Interestingly, prolamin caused a decline in eating quality, the reason is that prolamin in rice hindered the development of starch reticular structure. And prolamin was not easily digested and absorbed by the human body. The prolamin in rice grain was positively correlated with the highest viscosity of RVA, and negatively correlated with the hardness, viscosity and stickiness of starch gum (Baxter et al., 2010). The protein content of rice was higher, especially prolamin and glutelin content was higher. The integrity of rice was better, which increased elasticity and hardness of rice, was not easy to break, reduced the viscosity of rice, and finally improved the comprehensive taste of rice (Wang et al., 2016). The eating quality of rice grain was influenced by glutenin content and total protein content. The effect of total protein content on eating quality varied with the content of glutenin relative to prolamin (Wu et al., 2009). Gluten and prolamin in rice grain had negative effects on rice taste and starch RVA spectrum. A significant negative correlation was reached between glutenin, prolamin and the highest viscosity (Zhang et al., 2010). The effects of different proteins of the different rice varieties on rice eating quality are not the same. In a certain range of low-protein content, the increase of protein content could improve the eating quality of rice. In the breeding and cultivation of high-quality rice, the lower the grain protein content, the better the grain quality in rice. Due to the difference of protein content, composition and distribution in rice grain, the ability of combining water in the cooking process is different. At the same time, the disulfide bond and covalent bond of protein and the interaction between protein and starch will ultimately affect the grain eating quality of rice.

\section{The Relationship Between Lipid and Grain Quality Traits in Rice}

The lipid content is low in rice grain, however, it plays an important role in cooking quality, processing quality, nutritional quality and appearance quality of rice. Lipids in rice grain mainly include fat and phospholipids, which are important nutrients in rice, mainly distributed in the embryo and aleurone layers of rice seeds. In rice grains, lipids often form complexes with amylose (Xu et al., 2015; Goufo et al., 2014). Fatty acid oxidase was an important factor in reducing the nutritional quality of rice because it could catalyze lipid oxidation (Long et al., 2013). Extremely long-chain polyunsaturated fatty acids and long-chain polyunsaturated fatty acids were essential regulators of cholesterol and arachidonic acid synthesis and maintenance of cell membrane transport (Wysoczański et al., 2016). They're the main components of nerve cells, affecting the development and health of the human body (Puaschitz et al., 2015). Therefore, proteins or enzymes encoded by many genes were helpful to improve the level of ultra-long chain polyunsaturated fatty acids (Sun et al., 2015). Oil proteins were abundant in the oil bodies of plant seeds, and could be used to regulate the content of seed fat. Using the promoter of rice endosperm specific expression to drive the overexpression of soybean oil protein gene, the fat content in transgenic rice grains increased by more than $36 \%$, however, the total triglyceride fatty acid content did not change significantly (Liu et al., 2013). Rice oil 
contained a large number of antioxidant substances, such as oryzanol, lecithin, tocopherol and tocotrienol, which were very beneficial to human health (Choi et al., 2016). At present, although important progress has been made in the study of lipid metabolism in rice, it is still unclear how the lipid metabolism pathway in rice grains is finely regulated.

The contents and components of lipids in rice grain had a great influence on the grain quality of rice cooking. Rice fatty acids contain oleic acid, linoleic acid, soft fatty acid, small amounts of stearic acid and linolenic acid. The proportion of unsaturated fatty acids in rice fat was high, and it was easy to be oxidized by oxygen and related enzymes, which would adversely affect the color and palatability of rice, resulting in rice deterioration (Morrison et al., 1984). Studies have shown that crude fat content was significantly positively correlated with the color, appearance and alkali elimination of rice (Wu et al., 2002). The effects of lipid and protein on rice gelatinization could not be ignored (Mestres, 2011). The phospholipids and glycolipids contained in grain could interact with starch in rice, thus reducing the water absorption and swelling of starch and increasing the gelatinization temperature of starch. The complex of amylose and fat could hinder the gelatinization of starch, which may affect the texture of rice after cooking (Larssonet, 2012). The results showed that the degreasing rate of brown rice was lower than that of milled rice, but the decrease of DSC peak temperature was larger, which indicated that the lipid and non-starch lipid on the surface of rice affected the gelatinization of starch (Champagne et al., 2009). In the study of gelatinization of rice starch, it was found that the gelatinization temperature of non-defatted rice flour was lower than that of defatted rice flour, and the existence of oil would cause fluctuation of baseline, which may be related to degreasing method. The effects of amylopectin, amylose and lipids on the swelling and gelatinization of rice starch were also studied (Richard, 2009). It was found that starch swelling was the characteristic of amylopectin, while amylose only acted as a diluent. Amylose and lipids in natural starch could inhibit starch swelling when they form complex.

Improving the efficiency of phosphorus absorption and utilization is helpful to improve the nutritional quality of rice. The changes of phytic acid, lysophosphatidylcholine and inorganic phosphorus in grains have certain effects on the grain quality of rice. The mutation of $O S S T$ and OSMIK genes resulted in the decrease of LPLs and LPL-P content in rice grains; the mutation of OsMRP5 and Os2-PGK genes resulted in the increase of LPLs components and corresponding LPL-P contents (Tong, 2016). Starch can form starch fat complex by hydrophobic interaction with fatty acid molecules, which is similar to starch iodine. The composite index can reflect the degree of starch and fatty acid complex. When the same concentration of fatty acid was added to different samples, the composite index increased with the increase of amylose content in starch (Liu, 2006). For the same sample, the composite index increased with the increase of fatty acid concentration (Hu et al., 2007). When the amount of fatty acid was less than or equal to $2.0 \%$, the composite index of stearic acid and rice starch was significantly higher than that of oleic acid, indicating that stearic acid was easier to combine with starch than oleic acid. Rice starch with different amylose content can be compounded with oleic acid and stearic acid in varying degrees. The amount of complex formed by stearic acid and rice starch was greater than that of oleic acid at the same dosage, but the degree of complex tended to be the same when the concentration was more than $2 \%$. With 
the increase of fatty acid dosage, the compound content of the rice starch, oleic acid and stearic acid increased, the absorbance decreased and the composite index also increased.

\section{The Relationship Between Nutrient Elements and Grain Quality Traits in the Rice}

In recent years, due to the increase of pollutant emission and the excessive emission in some areas, the farmland pollution in China is becoming more and more serious. The situation of local treatment and overall decline is serious, especially the heavy metal pollution. According to the "National Soil Pollution Survey Bulletin" released in 2014, 16.1\% of the soils in China are polluted to varying degrees, among which the slight, mild, moderate and severe pollution accounts for $11.2 \%, 2.3 \%, 1.5 \%$ and $1.1 \%$ respectively, and the cadmium contaminated soil reaches $7.0 \%$. Heavy metal pollution was the main form of soil inorganic pollution, and rice was the most affected (Wen et al., 2019). Therefore, more attention has been paid to the safe utilization of cadmium contaminated paddy fields. The pollution area of heavy metals, especially cadmium, in paddy fields in Asia had been expanding, which had become an important factor restricting the sustainable development of rice (Wen et al., 2019). Some studies shown that soil $\mathrm{pH}$ and organic matter content determine the activity and bioavailability of cadmium, and the content of trace elements in the soil also directly or indirectly affects the activity and bioavailability of cadmium (Ye et al., 2019). Therefore, alkaline substances (e.g. lime, calcium magnesium phosphate fertilizer, etc.) or organic substances (e.g. humic acid, etc.) are commonly used as passivators to reduce the activity and bioavailability of cadmium in soil. As the most commonly used chemical modifier, lime can improve soil $\mathrm{pH}$, promote the formation of carbonate and hydroxide precipitation of heavy metals, so as to reduce the availability of cadmium in soil and reduce the absorption of cadmium by plants. Phosphorus in FCMP can interact with cadmium in contaminated soil through dissolution and precipitation, which can reduce the bioavailability of cadmium in soil, change the distribution of cadmium in soil, and promote the transformation of cadmium from exchangeable state to carbonate bound state and manganese oxide bound state. The adsorption and complexation of heavy metal ions by organic matter can promote the transformation of heavy metals from high active state to low active state.

Mineral elements, some as plant components, some regulate plant physiological functions, and some have both functions. Mineral elements mainly existed in the soil, which were absorbed by roots and transported to corresponding parts for assimilation for growth and development (Peng et al., 2014). Therefore, mineral elements have a great impact on the life activities of plants. The effects of mineral nutrition on rice grain quality not only existed differences among varieties and quality indicators (characteristics), but also in the process of rice quality formation, different types of mineral nutrients played different roles and the degree of action was not consistent. There were also some interaction effects (synergism or antagonism) among various mineral elements, which further proved that the relationship between grain quality and mineral nutrition was very complex in rice (Zhang and Cui, 2017). Therefore, it is very difficult and impractical to improve all the indexes of grain quality in rice. In the production of high-quality rice, it is necessary to consider the type of fertilizer, the amount of fertilizer, the proportion of fertilizer before and after the growth period and the coordination among different quality indicators. Different management measures should be taken for 
different rice varieties, and the fertilization scheme should be determined according to the quality characteristics of rice, so as to improve the comprehensive quality of rice.

\subsection{Effects of Major Fertilizer Nutrients on Rice Quality}

The main function of nitrogen lies in that it is the main component of living material protein. The nitrogen content of protein is $16-18 \%$. Nitrogen is also a component of nucleic acid, which is an important component of cells. The growth and development of plants is actually the growth of cells. Without nitrogen, new cells are difficult to form, and the growth and development of plants will be stagnant. Therefore, nitrogen had a significant effect on the growth of roots, branches and leaves. Among all the mineral elements, nitrogen nutrition has the most direct effect on grain quality and has the greatest influence degree in rice (Zhang and Cui, 2017). Generally speaking, the increase of nitrogen application during the whole growth period is beneficial to the improvement of grain processing quality and nutritional quality. The results showed that the gelatinization temperature of rice increased, the gelatinization temperature of rice increased, the gel consistency and the highest viscosity value, hot paste viscosity value, final viscosity value and disintegration value of RVA spectrum decreased, and the rice grain became hard and rough. The same amount of nitrogen application during the whole growth period and the application of fertilizer in different times or the former fertilizer moved backward could prevent rice premature senescence, maintain root activity and leaf photosynthetic capacity, and improve grain processing quality without reducing yield in rice.

Different from nitrogen and phosphorus, potassium exists mainly as ionic or soluble salts or adsorbed on the surface of protoplast, rather than in the form of organic compounds. Potassium is the activator of many enzymes, and enzymes are used as catalysts in the metabolism process. Without the role of enzymes, many physiological processes can't be carried out. Potassium could promote the photosynthesis of rice and promote the synthesis and transportation of carbohydrate ( $\mathrm{Li}$ et al., 2015). Potassium could also promote protein synthesis. According to the research, there was about 1 gram of potassium in 20 grams of protein. Therefore, potassium deficiency affected protein synthesis, and cell formation was inhibited, which was one of the important reasons why tillers were greatly affected when rice was deficient in potassium. Potassium can enhance the toughness of crop stalks, enhance the lodging resistance and disease and insect resistance of crops such as rice flax leaf spot disease can be alleviated. Potassium can improve the drought resistance and cold deficiency ability of crops due to the fact that potassium can maintain the normal water content of cells, reduce transpiration loss of water and improve the sugar content of crops. If potassium was deficient, rice water content decreased and root cells senesce quickly (Xu et al., 1990). The experiment showed, that with the increase of potassium application, the grain fullness was significantly improved, the percentage of whole rice was increased, and the chalkiness rate and chalkiness area were decreased. In addition, potassium fertilizer application can improve the lodging resistance of rice, enhance the anti-aging ability of rice in the later stage of growth, prolong the time of filling and setting, and then improve grain quality in rice.

Phosphorus was a component of many important compounds in plants, and participates in planting in many ways to cause root dysplasia, plant growth arrest, and the phenomenon of 
"stiff seedling" often encountered in production (Shi et al., 2010). Phosphorus is also a component of phospholipid, phytin and adenosine triphosphate (ATP). Phospholipids are components of cellular biofilms, plant is a special storage form of phosphorus in seed and it can promote the synthesis of starch. The adenosine triphosphate is a high energy substance that can provide energy for many biochemical processes. In addition, many enzymes also contain phosphorus. Phosphorus is closely related to the main metabolic processes of crops. Firstly, phosphorus can promote the synthesis and transportation of carbohydrates. Secondly, phosphorus plays an important role in the synthesis and decomposition of proteins, and severe phosphorus deficiency can only decompose proteins without synthesis; and phosphorus can also promote fat synthesis. Therefore, the application of the phosphorus fertilizer had a good effect on improving the protein, sugar and oil content of the effect (Shi et al., 2010). Phosphorus can improve the ability of crops to adapt to the environment. It can enhance the ability of crops to resist drought and cold. Because phosphorus can enhance the ability of cells to resist dehydration and bear higher temperatures, phosphorus can promote the growth and development of roots, and can regulate many important metabolic processes in crops. And most interesting, phosphorus could enhance the ability of crops to influence the changes of acid-base in external conditions on crops, that was, buffer capacity (Zhang and Cui, 2017). The abundant content of available phosphorus in soil was conducive to reducing chalkiness rate and improving grain processing quality (e.g. milled rice rate) and appearance quality. Rice yield increased significantly with the increase of phosphorus fertilizer application. Increased application of phosphorus fertilizer could increase the soluble sugar and starch content of grains, protein nitrogen and total nitrogen content of leaves and grains, and the contents of cystine, cysteine, methionine and sulfur-containing amino acids in rice grains also increased to varying degrees (Zhang and Cui, 2017). The application period and dosage of phosphorus fertilizer had no obvious effect on amylose content and recovery value of rice, but had obvious effect on the highest viscosity value and disintegration value of rice. The two characteristic values were the highest when all the treatments were used as base fertilizer resources, and the highest viscosity value of phosphorus fertilizer in the later stage had a tendency to decrease.

\subsection{Effects of Micronutrient Element on Rice Quality}

The content of micronutrient elements in soil is very low, generally only a few parts per million, but it plays a very large role, and has strong specificity. It is an indispensable element for rice growth. In the experiment of the high quality rice production technology system and its application theory research cooperation group, spraying $0.05 \%$ ammonium molybdate solution at booting and heading stage could increase head rice rate and reduce chalkiness rate (Xu et al., 2010). Iron, cobalt, vanadium, nickel and other elements could also significantly reduce the chalkiness rate and improve the grain appearance quality of rice (He et al., 2010). Single or mixed application of copper, zinc, molybdenum and manganese could increase amylose content, while combined application of molybdenum and manganese could significantly increase protein content. Mainly because manganese was involved in photosynthesis, molybdenum could increase photosynthetic intensity of crops and promoted the assimilation of nitrate nitrogen, thus promoting protein synthesis. Single or combined application of copper and zinc reduced the protein content in rice by a small margin. 
With the improvement of people's living standard, people's requirements for mineral nutrients in daily diet are also increasing. Thus, it becomes very important to excavate rice germplasm resources rich in beneficial elements and provide parental resources for cultivating excellent varieties rich in beneficial elements. 533 rice varieties with mineral nutrient enrichment were screened based on the above average contents of $\mathrm{N}, \mathrm{Mg}, \mathrm{K}, \mathrm{Ca}, \mathrm{Mn}, \mathrm{Fe}, \mathrm{Cu}$ and $\mathrm{Zn}$ in brown rice (Qiu, 1992), The results showed that cultivars No. 20, No. 41, No. 42 and No. 246 contained higher contents of $\mathrm{N}, \mathrm{Mg}, \mathrm{K}$ and $\mathrm{Ca}$ (data are shown in Table 2), and the Zn contents of cultivars No. 20 and No. 41 were also higher, cultivars No. 42 and No. 246 also contained higher $\mathrm{Fe}$ and $\mathrm{Cu}$, respectively. Cultivars No. 226, No. 278 and No. 482 contained higher contents of $\mathrm{Mg}, \mathrm{K}, \mathrm{CA}, \mathrm{Mn}, \mathrm{Cu}$ and Zn. Cultivars No. 2, No. 218, No. 384 and No. 483 are rich in micronutrient elements. The varieties No. 384 and No. 483 had higher contents of Mn, $\mathrm{Cu}$ and $\mathrm{Zn}$, as well as rich $\mathrm{Mg}$ and $\mathrm{K}$ elements. These rice varieties could be used as good parent in the future breeding work (Dong, 2014).

\section{Prospection}

Along with the deepening of rice scientific research and the improvement of residents' consumption level, breeders and consumers put forward higher requirements for rice grain of quality, which not only requires good appearance of rice, but also requires rice to have good taste quality (Zhang et al., 2007). Therefore, it is one of the most urgent tasks for rice quality breeding in China to improve grain quality, speed up the process of grain quality improvement and formulate new rice quality evaluation standards. The contents of protein and lipid in grain of rice are relatively low, however, they have great influence on cooking quality, storage quality, nutritional quality and appearance quality of rice. Therefore, this paper reviews the relationship between the main nutrients such as starch, protein, lipid and micronutrient elements in rice and their grain quality traits, which is of great theoretical significance and potential application value for the continuous improvement of grain quality in the future. In particular, the effects of the main nutrients in rice, including starch, protein, lipid and micronutrient elements, on the main traits of grain quality in rice were analyzed. This will provide important information for genetic improvement of grain quality and breeding of new varieties of high quality rice.

Table 2. Soybean and rice varieties with high nutrient elements content

\begin{tabular}{ccccccccc}
\hline \multirow{2}{*}{$\begin{array}{c}\text { ID of } \\
\text { Variety }\end{array}$} & \multicolumn{8}{c}{ Content of mineral elements } \\
\cline { 2 - 9 } Number & $\mathrm{N}(\mathrm{mg} / \mathrm{g})$ & $\mathrm{Mg}(\mathrm{mg} / \mathrm{g}) \mathrm{K}(\mathrm{mg} / \mathrm{g})$ & $\mathrm{Ca}(\mu \mathrm{g} / \mathrm{g})$ & $\mathrm{Mn}(\mu \mathrm{g} / \mathrm{g})$ & $\mathrm{Fe}(\mu \mathrm{g} / \mathrm{g})$ & $\mathrm{Cu}(\mu \mathrm{g} / \mathrm{g})$ & $\mathrm{Zn}(\mu \mathrm{g} / \mathrm{g})$ \\
\hline 2 & 20.08 & 1.82 & 4.86 & 168.89 & 38.59 & 354.92 & 15.60 & 36.47 \\
20 & 23.30 & 2.26 & 5.11 & 230.82 & 60.65 & 168.84 & 6.78 & 33.13 \\
41 & 24.70 & 2.02 & 5.21 & 236.50 & 49.92 & 77.81 & 3.21 & 33.31 \\
42 & 21.23 & 2.70 & 5.79 & 233.82 & 66.62 & 427.71 & 6.21 & 33.80 \\
218 & 20.08 & 1.72 & 3.76 & 218.22 & 66.47 & 248.80 & 7.72 & 35.99 \\
226 & 16.06 & 2.63 & 4.47 & 445.49 & 95.75 & 28.84 & 8.65 & 48.53 \\
246 & 22.52 & 2.19 & 4.71 & 223.64 & 38.20 & 184.76 & 8.21 & 27.78 \\
278 & 19.86 & 1.93 & 4.68 & 269.59 & 82.12 & 48.21 & 10.23 & 45.38
\end{tabular}




\begin{tabular}{ccccccccc}
\hline 384 & 14.01 & 2.18 & 5.45 & 162.10 & 87.95 & 46.04 & 8.97 & 52.17 \\
482 & 16.06 & 2.22 & 5.03 & 263.06 & 131.63 & 18.96 & 9.32 & 66.30 \\
483 & 16.73 & 2.27 & 4.75 & 196.84 & 90.03 & 36.73 & 8.96 & 60.52 \\
Mean & 17.77 & 1.67 & 3.76 & 163.30 & 50.02 & 99.46 & 5.23 & 25.53 \\
SD & 2.32 & 0.24 & 0.56 & 50.80 & 18.15 & 96.72 & 2.34 & 7.46 \\
\hline
\end{tabular}

\section{Acknowledgments}

This work was financially supported by National Natural Science Foundation of China (U1604110, 31600992, 31801332), Key Project of Science and Technology in Henan Province (192102110119, 182102110442), Open Project of State Key Laboratory of Hybrid Rice in Wuhan University (KF202001), National Key R\&D Program Projects (2016YFD0100101-10), The Training Plan of Young Backbone Teachers in Colleges and Universities of Henan Province (2019GGJS162), Key Scientific Research Projects of Universities in Henan Province (21A180001, 19A180030), Nanhu Scholars Program for Young Scholars of XYNU (2016054).

\section{References}

Ahmadi-Abhari, S., Woortman, A. J. J., \& Hamer, R. J. (2013). Influence of lysophosphatidylcholine on the gelation of dilutedwheat starch suspensions. Carbohydrate Polymers, 93(1), 224-231. https://doi.org/10.1016/j.carbpol.2012.05.020

Baxter, G., Zhao, J., \& Blanchard, C. (2010). Albumin significantly affects the pasting and textural characteristics of rice flour . Cereal Chemistry, 87(3): 50-255. https://doi.org/10.1094/CCHEM- 87-3-0250

Bergman, C. J., Bhattacharya, K. R., \& Ohtsubo, K. (2004). Rice end-use quality analysis, in: Rice: Chemistry and Tehcnology. AACC, Champagne, ET, Plant Physiology. 415-472.

Bett-Garber, K. L., Champagne, E. T., Ingram, D. A., \& McClung, A. M. (2007). Influence of water-to-rice ratio on cooked rice flavor and texture. Cereal Chemistry, 84, 614-619. https://doi. org/10.1094/CCHEM-84-6-0614

Bett-Garber, K. L., Champagne, E. T., McClung, A. M., Moldenhauer, K. A., Linscombe, S. D., \& McKenzie, K. S. (2001). Categorizing rice cultivars based on cluster analysis of amylase content, protein content and sensory attributes. Cereal Chemistry, 78, 551-558. https://doi.org/10.1094/ CCHEM.2001.78.5.551

Bett-Garber, K. L., Lea, J. M., Mc-Clung, A. M., \& Chen, M. H. (2013). Correlation of sensory, cooking, physical, and chemical properties of whole grain rice with diverse bran color. Cereal Chemistry, 90, 521-528. https://doi.org/ 10.1094/CCHEM-10-12-0126-R

Bhattacharya, K. R., Sowbhagya, C. M., Swamy, I., \& Yelandur, M. (1978). Importance of insoluble amylose as a determinant of rice quality. Journal of the Science of Food and Agriculture, 29, 359-364. https://doi.org/ 10.1002/jsfa.2740290410

Brittani, E., Margarita, V., Christopher, B., James, L., Dayton, L., Roland, R., ... Larry, F. (2018). Automatic section control technologies and GPS auto-guidance systems adoption in 
$\begin{array}{llllll}\text { cotton production. Journal of Agricultural Science, } & \text { 10(7), } & 282 .\end{array}$ https://doi.org/10.5539/jas.v10n7p156

Cai, Y. X., Zhu, Z. W., Wang, W., Zhang, Z. J., \& Zhu, Q. S. (2005). Studies on the relationships of amylose content with the grain quality and the texture of cooked rice. Journal of YangZhou University, 26(4), 52-55. https://doi.org/10.16872/j.cnki.1671-4652.2005.04.014

Calingacion, M., Laborte, A., Nelson, A., Resurreccion, A., Concepcion, J. C., Daygon, V. D., ... Fitzgerald, M. (2014). Diversity of global rice markets and the science required for consumer-targeted rice breeding. PLoS One, 9(1), e85106. https://doi.org/10.1371/journal.pone.0085106

Calingacion, M., Laborte, A., Resurreccion. A., Bao, J., Xie, L., Reinke, R., ... Nelson. A., (2014). Diversity of global rice markets and the science required for consumer-targeted rice breeding. PLoS One, 9(1), e85106. https://doi.org/10.1371/journal.pone.0085106

Champagne, E. T. (1996). Rice starch composition and characteristics. Cereal Foods WOrld, 41(11), 833.

Champagne, E. T., Bett-Garber, K. L., McClung, A. M., \& Bergman, C. (2004). Sensory character-Istics of diverse rice cultivars as influenced by genetic and environmental factors. Cereal Chemistry, 81, 237e243. https://doi.org/ 10.1094/CCHEM.2004.81.2.237

Champagne, E. T., Bett-Garber, K. L., Thompson, J., Mutters, R., Grimm, C. C., \& McClung, A. M. (2005). Effects of drain and harvest dates on rice sensory and physicochemical properties. Cereal Chemistry, 82, 369-374. https://doi.org/10.1094/CC-82-0369

Champagne, E. T., Bett-Garber, K. L., Thomson, J. L., \& Fitzgerald, M. A. (2009). Unraveling the impact of nitrogen nutrition on cooked rice flavor and texture. Cereal Chemistry, 86, 274-280. https://doi.org/ 10.1094/CCHEM-86-3-0274

Chang, Q. Z., Dong, S. Z., Qian, F., Li, M. H., G. U., \& Qiao, Q. L. (2016). Progresses in research on cloning and functional analysis of key genes involving in rice grain quality. Entia Agricultura Sinica, 49(22), 4267-4283. https://doi.org/10.3864/j.issn.0578-1752.2016.22.002

Cheetham, N. W. H., \& Tao, L. V. (1998). Variation incrystalline type with amylose content in maize starch granules: An-ray powder diffrction study. Carbohydrate Polymers, 36(4): 277-284. https://doi.org/10.1016/S0144-8617(98)00007-1

Choi, N., Lee, J. S., Kwak, J., Lee, J., \& Kim, I. H. (2016). Production of biodiesel from acid oil via a two-step enzymatic transesterification. Journal of Oleo Science, 65(11), 913-921. https://doi. org/10.5650/jos.ess 16092

Dong, H. X. (2014). Analysis of mineral element content of brown rice in rice germplasm resources. Huazhong Agricultural University.

Duan, M., \& Sun, S. S. M. (2005). Profiling the expression of genes controlling rice grain quality. Plant Molecular Biology, 59(1), 165-178. https://doi.org/10.1007/s11103-004-7507-3

Fitzgerald, M. A., McCouch, S. R., \& Hall, R. D. (2009). Not just a grain of rice: the quest for quality. Trends in Plant Science, 14, 133-139. 
https://doi.org/10.1016/j.tplants.2008.12.004

Ge, Z. G., Zang, Z., Shi, C. H., Wu, J. G., \& Ye, Z. H. (2007). Impacts of Amylose Content or Protein Content on Genetic Correlations Between the Weight of Brown Rice and Appearance Quality Traits of Rice. Chinese Journal of Rice Science, 21(1), 44-50. https://doi.org/10.16819/j. 1001-7216. 2007.01.008

Goufo, P., Falco, V., Brites, C. M., Wessel, D. F., \& Trindade, H. (2014). Effect of elevated carbon dioxide concentration on rice quality: nutritive value, color, milling, cooking, and eating qualities. Cereal Chemistry, 91, 513-521. https://doi.org/10.1094/CCHEM-12-13-0256-R

Gu, D. D., Liu, Z. H., Liu, Y., Wang, S. H., Wang, Q. S., Li, G. H., \& Ding Y. F. (2011). Effect of lipid content and components on cooking quality and their response to nitrogen in milled japonica rice. Acta Agronomica Sinica, 37(11), 2001-2010. https://doi.org/10.3724/SP.J.1006. 2011.02001

He, X., Zhu, C., \& Liu. L. L. (2010). Difference of amylopectin structure among rice varieties differing in grain quality and its correlations with starch physicochemical properties. Acta Agronomica Sinica, 36(2), 276-284. https://doi.org/10.1016/S1875-2780(09)60035-3

He, Y., Wang, S., \& Ding, Y. (2013). Identification of novel glutelin subunits and a comparison of glutelin composition between Japonica and indica rice (Oryza sativa L). Journal of Cereal Science, 57(3), 362-371. https://doi.org/10.1016/j.jcs.2012.12.009

Hu, Z. P., Zhong, H. M., Yang, C. L., Huang, R. F., \& Liu, M. N. (2007). Advance in forming regularity of rice quality and its breeding technical strategies. Acta Agriculturae Jiangxi, 17(6), 5-11.

Hu, Z. Z., Cheng, X. N., Yuan, Z. K., Zhang, J., li, J. Z., Peng, T., ... Zhao, Q. Z. (2020). Grain quality characters and their correlations of 135 japonica rice germplasm resources in Henan rice-growing regions alongside the Yellow River. Journal of Henan Agricultural Sciences. https://kns.cnki.net/kcms/detail/41.1092.S.20200616.1051.002.html

Huang, F. S., Sun, Z. X., Hu, P. S., \& Tang, S. Q. (1999). Present situations and prospects for the research on rice grain quality forming. Chinese Journal of Rice Science, 11(2), 70-76. https://doi.org/10.16819/j.1001-7216.1998.03.009

Ji, Q. E., Zheng, H. Q., Xu, X. Z., \& Lan, S. Y. (1998). Observation on the microstructure of endosperm starch granule of rice with different qualities. Journal of Fujian Agriculture and Forestry University (Natural Science Edition), 27(2), 241-244. https://doi.org/CNKI:SUN:FJND.0. 1998-02-022

Jiao, A. X., Yang, C. R., Cao, G. L., Li, D. H., Guo, J. C., Jin, Z. H. ... Han, L. Z. (2008). Progress in Genetic Research on Protein Content of Rice. Scientia Agricultura Sinica, 41(1), $1-8$.

Jiao, A. X., Yang, C. R., Cao, G. L., Li, D. H., Guo, J. C., Kim, J. H., .. Han, L. Z. (2008). Progress in genetic research on protein content of rice. Scientia Agricultura Sinica, 41(1), $1-8$.

Jin, L. C. (2010). Correlations between physicochemical properties, molecular structure of 
rice starch and rice eating quality. Universities directly under the Ministry of Education.

Juliano, B. O. (2007). Rice chemistry \& Quality, Rev. ed. Philippine Rice Research Institute, Science City of Munoz, Nueva Ecija.

Juliano, B. O., \& Perez, C. M. (1983). Major factors affecting cooked milled rice hardness and cooking time. Journal of Texture Studies, 14, 235-243.

Juliano, B. V. O., Perez, C. M., Barber, S., Blakeney, A. B., Iwasaki, T., Shibuya, N., ... Lee, L. F. (1999). Effects of amylopectin branch chain length and amylase content on the gelatinization and pasting properties of starch. Cereal Chemistry, 76(5), 629-637. https://doi.org/10.1094/ CCHEM.1999.76.5.629

Kawakatsu, T., Hirose, S., Yasuda, H., \& Takaiwa, F. (2010). Reducing rice seed storage protein accumulation leads to changes in nutrient quality and storage organelle formation. Plant Physiology, 154(4), 1842-1854. https://doi.org/10.1104/pp.110.164343

Kim, S. S., Lee, S. E., Kim, D. C., \& Kim, O. W. (2000). Physicochemical Characteristics of Chalky Kernels and Their Effects on Sensory Quality of Cooked Rice. Cereal Chemistry, 77(3), 376-379. https://doi.org/ 10.1094/CCHEM.2000.77.3.376

Kong, L. X., Zhu, P., Bao, J. S., \& Sui, Z. Q. (2015). Physicochemical properties of starches from diverse rice cultivars varying in apparent amylose content and gelatinization temperature combinations. Food Chemistry, 172, 433-440. https://doi.org/10.1016/j.foodchem.2014.09.085

Krishnan, H. B., \& Oita, T. W. (1986). Structural relationship among the rice glutelin, polypeptides. Plant Physiology, 81(3), 748-753. https://doi.org/10.1104/pp.81.3.748

Li, D. D., Zhen, G. P., Cai, Y. S., \& Yin, D. W. (2015). Relationship between chalkiness index and other quality characters of japonica rice. Jiangsu Agricultural Scuiences, 43(6), 70-72. https://doi.org/ 10.15889 issn.1002 -1302. 2015. 06. 020

Li, D. L., Zhang, J. M., Wang, H., Li, M. Z., \& Piao, Z. Z. (2010). Differences in amylopectin structure and grain quality of rice between some high-quality japonica cultivars from the lower Yangtze River Region, China and Koshihikari from Niigata, Japan. Chinese Journal of Rice Science, 24(4), 379-384. https://doi.org/10.3969/j.issn.1001-7216.2010.04.008

Li, H. Z., Qiao, Q. L., Chang, Q. Z., Yong, X. U., \& Shu, Z. T. (2009). Variation and distribution of seed storage protein content and composition among different rice varieties. Acta Agronomica Sinica, 35(5), 884-891. https://doi.org/10.1016/ S1875-2780(11)60098-9

Li, H., Prakash, S., Nicholson, T. M., Fitzgerald, M. A., \& Gilbert, R. G. (2016). Instrumental measurement of cooked rice texture by dynamic rheological testing and its relation to the fine structure of rice starch. Carbohydrate Polymers, 146, 253-263. https://doi.org/10.1016/j.carbpol. 2016.03.045

Li, Q. H., Wang, F., Lin, C., He, C. M., Li, Y., Zhong, S. J., \& Lin, X. J. (2015). Effects of potassium fertilizer application on physiology and iron uptake and accumulation in rice plants in cold immersion fields. Acta agriculturae fujian, 30(3), 243-248. https://doi.org/10.3969/j.issn: 1008-0384.2015.03.007 


\section{MIMacrothink}

Liu, L., Waters, D. L. E., Rose, T. J., Bao, J., \& King, G. J. (2013). Phospholipids in rice: significance in grain quality and health benefits: a review. Food Chemistry, 139(1-4), 1133-1145. https://doi.org/ 10.1016/j.foodchem.2012.12.046

Liu, Q. H., Cai, J., Liu, M., Chai, T. Y., \& Li, T. (2007). Effect of chalkiness on cooking, eating and nutritional quality in two indica rice. Chinese Journal of Rice Science, 21(3), 327-330. https://doi.org/10.16819/j.1001-7216.2007.03.020

Liu, Y. (2006). Physico-chemical bases and grain filling cytochemical characteristics of rice quality differences development. Universities directly under the Ministry of Education.

Liu, Y. B., \& Huang, Y. J. (1989). The study on the relativity of flavor quality of rice. Acta Agriculturae Universitis Jiangxiensis, 4, 1-5.

Long, X., Liu, Q., Chan, M., Wang, Q., \& Sun, S. S. M. (2013). Metabolic engineering and profiling of rice with increased lysine. Plant Biotechnology Journal, 11(4), 490-501. https://doi.org/ 10.1111/pbi.12037

Lu, K., Li, L., Zheng, X., Zhang, Z., Mou, T., \& Hu, Z. (2009). Genetic dissection of amino acid content in rice grain. Journal of the Science of Food and Agriculture, 89(14), 2377-2382. https://doi.org/10.1002/jsfa.3731

Lyon, B. G., Champagne, E. T., Vinyard, B. T., Windham, W. R., Barton, F. E., Webb, B. D., ... Kohlwey, D. E. (1999). Effects of degree of milling, drying condition, and final moisture content on sensory texture of cooked rice. Cereal Chemistry, 76, 56-62. https://doi.org/10.1094/CCHEM. 1999.76.1.56

Matsue, Y., Sato, H., \& Uchimura, Y. (2001). The palatability and physicochemical properties of milled rice for each grain-thickness group. Plant Production Science, 4(1), 71-76. https://doi.org/ 10.1626/pps.4.71

Mestres, C., Briffaz, A., \& Valentin, D. (2019). Rice cooking and sensory quality. Rice

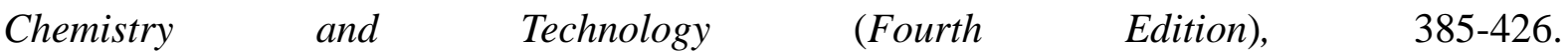
https://doi.org/10.1016/B978-0-12-811508-4.00012-5

Mestres, C., Ribeyre, F., Pons, B., Véronique Fallet, \& Matencio, F. (2011). Sensory texture of cooked rice is rather linked to chemical than to physical characteristics of raw grain. Journal of Cereal ence, 53(1), 81-89. https://doi.org/ 10.1111/j.1745-4603.1983.tb00346.x

Mo, H. D. (1994). Improvement of rice quality in China. Journal of Jiangsu Agricultural College, 1, 30. https://doi.org/ 10.16872/j.cnki.1671-4652.1994.01.007

Nakamura, Y., Sakurai, A., Inaba, Y., Kimura, K., Iwasawa, N., \& Nagamine, T. (2010). The fine structure of amylopectin in endosperm from asian cultivated rice can be largely classified into two classes. Starch-Strke, 54(3-4), 117-131. https://doi.org/10.1002/1521-379X(200204)54:3/43.0.CO;2-2

Ong, M. H., \& Blanshard, J. M. V. (1995). Texture determinants of cooked, parboiled rice. ii: physicochemical properties and leaching behaviour of rice. Journal of Cereal Science, 21(3), 261-269. https://doi.org/ 10.1006/jcrs.1995.0028 


\section{$\triangle$ Macrothink}

Peng, B., Kong, H., Li, Y., Wang, L., Zhong, M., Chen, J. X., ... Sun, L. (2014). OsAAP6 functions as an important regulator of grain protein content and nutritional quality in rice. Nature Communications, 5, 4847. https://doi.org/10.1038/ncomms5847

Peng, X. S., Zhu, C, L., Wang, F., He, X. P., Fu, J. R., Chen, X. R., ... He, H. H. (2014). The Relationship between Amylopectin Structure and Rice Pasteproperty of Indica/Japonica Cross Progenies. Journal of Nuclear Agricultural Sciences, 28(7), 1219-1225. https://doi.org/10.11869/j.issn.100-8551.2014.07.1219

Puaschitz, N. G., Strand, E., Norekvl, T. M., Dierkes, J., \& Nygrd, O. (2015). Dietary intake of saturated fat is not associated with risk of coronary events or mortality in patients with established coronary artery disease. Journal of Nutrition, 145(2), 299-305. https://doi.org/10.3945/jn.114. 203505

Qiu, L. C. (1992). To improve national quality and develop excellent food germplasm resources. China Rice Research Institute, Beijing: China Agricultural Science and Technology Press.

Ramesh, M., Bhattacharya, K. R., \& Mitchell, J. R. (2000). Developments in understanding the basis of cooked-rice texture. Critical Critical Reviews in Food Technology, 40(6), 449-460. https://doi.org/ 10.1080/10408690091189220

Rousset, S., Pons, B., \& Martin, J.F. (1999). Identifying objective characteristics that predict clusters produced by sensory attributes in cooked rice. Journal of Texture Studies, 30, 509-532. https://doi.org/ 10.1111/j.1745-4603.1999.tb01405.x

Shewry, P. R. (2007). Improving the protein content and composition of cereal grain. Journal of Cereal ence, 46(3), 239-250. https://doi.org/10.1016/j.jcs.2007.06.006

Shewry, P. R., \& Halford, N. G. (2002). Cereal seed storage proteins: structures, properties and role in grain utilization. Journal of Experimental Botany, 370, 947-958. http://dx.doi.org/10. 1093/jexbot/53.370.947

Shi, L. L., Zhang, X., Ding, D. L., Wang, W. S., \& Cui, J. (2010). Study on the correlation of rice physicochemical properties and palatability quality. Seed, 29(11), 82-84. https://doi.org/10.16590/j.cnki.1001-4705.2010.11.058

Shiki, J., Tsuji, S., Tokoyama, J., Tatsumi, K., \& Webb, B. D. (1981). International cooperative comparison of instrument methods for cooked rice texture. Journal of Texture Studies, 12, 17-38. https://doi.org/ 10.1111/j.1745-4603.1981.tb00533.x

Sowbhagya, C. M., Ramesh, B. S., \& Bhattacharya, K. R. (1987). The relationship between cooked-rice texture and the physicochemical characteristics of rice. Journal of Cereal Science, 5(3), 287-297. https://doi.org/ 10.1016/S0733-5210(87)80029-2

Srisawas, W., \& Jindal, V. K. (2007). Sensory evaluation of cooked rice in relation to water-to-rice ratio and physicochemical properties. Journal of texture studies, 38(1), 21-41. https://doi.org/ 10.1111/j.1745-4603.2007.00084.x

Sun, Q., Liu, J., Zhang, Q., Li, X. Z., Qi, B. X., Dobson, G., \& Qing, X. H. (2013). 
Characterization of three novel desaturases involved in the delta- 6 desaturation pathways for polyunsaturated fatty acid biosynthesis from phytophthora infestans. Applied Microbiology and Biotechnology, 97(17), 7689-7697. https://doi.org/ 10.1007/s00253-012-4613-z

Tian, S., \& Wang, X. P. (2014). Advancements on protein of rice. Natural science Journal of Harbin Normal University, 30(5), 91-95.

https://doi.org/10.3969/j.issn.1000-5617.2014.05.024.

Tian, Z. X., Qian, Q., Liu, Q. Q., Yan, M. X., Liu, X. F., Yan, C. J., .. Li, J. Y. (2009). Allelic diversities in rice starch biosynthesis lead to a diverse array of rice eating and cooking qualities. Proceedings of the National Academy of Sciences of the United States of America, 106(51), 21760-21765. https://doi.org/10.1073/pnas.0912396106

Tong, C. (2016). Identification of lysophospholipin in rice, genetic diversity and its relationship with quality. Zhejiang University.

Vandeputte, G. E., \& Delcour, J. A. (2004). From sucrose to starch granule to starch physical behaviour: a focus on rice starch. Carbohydrate Polymers, 58(3), 245-266. https://doi.org/10.1016/j.carbpol.2004.06.003

Vidal, V., Pons, B., Brunnschweiler, J., Handschin, S., Rouau, X., \& Mestres, C. (2007). Cooking behavior of rice in relation to kernel physicochemical and structural properties. Journal of Agricultural and Food Chemistry 55, 336-346. https://doi.org/ 10.1021/jf061945o

Wang, P. Y. (2016). Study on influence of rice protein and its composition on rice cooking and eating quality. Zhejiang Gongshang University.

Wang, Q. (2016). Physical and chemical foundation for cooking and eating quality of japonica rice. Universities directly under the Ministry of Education. https://doi.org/CNKI:CDMD:2.1017. 256389

Wang, R. X., Hai, L., Zhang, X. Y., You, G. X., Yan, C. S., \& Xiao, S. H. (2009). QTL mapping for grain filling rate and yield-related traits in rils of the chinese winter wheat population heshangmaixyu8679. Theoretical and Applied Genetics, 118(2), 313-325. https://doi.org/10.1007/ s00122-008-0901-5

Wen, J., Li, Z. S., Xu, W. L., Chen, G., Bai, L. Y., Zeng, X. B., \& Wang, J. M. (2019). Effects of lime and calcium magnesium phosphate fertilizers on the growth and cadmium content of late rice. Chinese journal of agricultural and environmental sciences, 38(11), 2496-2502. https://doi.org/ 10.11654/jaes.2019-0419

Wu, S. K., Liu, S. J., Jiang, L., Zhang, W. W., Wang, Y. H., Ren, Y. L., ... Liu, F. (2009). Relationship between protein composition and total protein content and starch RVA profile properties in rice. Chinese Journal of Rice Science. 23(4), 421-426. https://doi.org/10.3969/j.issn. 1001-7216.2009.04.13

Wysoczański, T., Sokoła-wysoczańska, E., Librowski, T., Bodkowski, R., Herbinger, G., Patkowska-Sokoła B ... Pękala, J. (2016). Omega-3 fatty acids and their role in central nervous system-a review. Current Medicinal Chemistry, 23(8): 816-831. https://doi.org/10.2174/ 0929867323666160122114439 
Xiang, Y. H., Tang, Q. Y., \& Huang, Y. X. (1990). The relativity of rice grain quality characteristics-I. Relations between eating quality and other grain quality characteristics of indica non-Waxy rice. Journal of Hunan Agricultural College, 16(4), 325-330. https://doi.org/10. 13331/j.cnki.jhau.1990.04.002

Xie, X. H., Xiao, X., Li, X. F., \& Liu, L. W. (2003). Research progress of rice protein. Guangdong Agricultural Science, 6, 2-4.

https://doi.org/10.16768/j.issn.1004-874x.2003.06.001

Xu, D. Y., Jin, J., Hu, S. J., Gao, Y., Yang, J. C., \& Zhu, Q. S. (2005). Influence of Nitrogen,Phosphorus and potassium fertilizer operation on amylopectin content and characteristic Parameters of starch viscosity spectrum in rice. Acta Agriculture Sinica, 7, 921-925. https://doi. org/10.3321/j.issn:0496-3490.2005.07.017

Xu, G. Q., Tong, H., Hu, J. H., Liu, H. M., \& Li, X. Z. (2015). Cultivar difference of rice protein components and their relationship with rice quality. Journal of Hunan Agricultural University (Natural Sciences), 41(1), 7-11. https://doi.org/10.13331/j.cnki.jhau.2015.01.002

Xu, H., Wei, Y., Zhu, Y., Lian, L., \& Zhang, J. (2015). Antisense suppression of lox3 gene expression in rice endosperm enhances seed longevity. Plant Biotechnology Journal, 13(4), 526-539. https://doi.org/10.1111/pbi.12277

Yang, Z. M., Wang, W. J., Lan, S. Y., Xu, Z. X., Zhong, F. X., \& Wang, M. (2003). Separation of three types of starch fractions in rice and the microstructures of endosperms before and after gelatinization. Journal of Chinese Electron Microscopy Society, 22(4), 286-291. https://doi.org/ 10.3969/j.issn.1000-6281.2003.04.006

Yao, Y., \& Guiltinan, T. M. J. (2004). Maize starch-branching enzyme isoforms and amylopectin structure. in the absence of starch-branching enzyme iib, the further absence of starch-branching enzyme ia leads to increased branching. Plant Physiology, 136(3), 3515-3523. https://doi.org/ 10.1104/pp.104.043315

Ye, G. Y., Liang, S. S., \& Wan, J. M. (2010). QTL mapping of protein content in rice using single chromosome segment substitution lines. Theoretical and Applied Genetics, 121(4), 741-750. https://doi.org/10.1007/s00122-010-1345-2

Ye, J. W., Jin, Y. M., Li, X. J., Ao, Y. S. (2019). Effects of soil texture, pH and organic matter content on cadmium morphology and its mechanism. Journal of Shanghai Jiao Tong University (Agricultural Science Edition), 37(3), 29-33. https://doi.org/10.3969/J.ISSN

Zhang, C. Q., Zhao, D. S., Li, Q. F., Gu, M. H., \& Liu, Q. Q. (2016). Progresses in research on cloning and functional analysis of key genes involving in rice grain quality. Scientia Agricultura Sinica, 49(22), 4267-4283. https://doi.org/10.3864/j.issn.0578-1752.2016.22.002

Zhang, L. G., \& Xi, X. J. (2007). Farm produce quality-grading standard remains basis for enhanced competitiveness. International Agriculture Trade, 2, 14-17.

Zhang, X. M., Zhou, R. F., \& Feng, L. (1998). Chang of rice lipids during storage and its effects on rice gelatinization. Journal of Chinese Cereals and oils Association, 3, 16-20. https://doi.org/ 10.3321/j.issn:1003-0174.1998.03.005

Zhang, X., Shi, L. L., Liu, X. Y., Ding, D. L., Wang, S. W., \& Cui, J. (2010). Effect of different fertilizer treatments on rice yield, grain quality and protein fraction content. Chinese 
Agricultural Science Bulletin, 26(4), 104-108.

Zhao, X. W., Bian, K., Wang, J. S., \& Zhou, Z. M. (1998). Effect of interaction of protein and starch on texture characteristics of aged rice. Journal of Zhengzhoou Graln College, 19(3), 23-29. https://doi.org/10.16433/j.cnki.issn1673-2383.1998.03.003

Zhong, H. M., Liu, M. N., Yan, C. L., Huang, R. Fen., \& Hu, Z. P. (2007). Advance in forming regularity of rice quality and its breeding technical strategies. Acta Agriculturae Jiangxi, 19(6), 5-11. https://doi.org/10.19386/j.cnki.jxnyxb.2007.06.002

Zhou, H. Y., Peng, X. S., Zhu, C. L., Chen, X. R., Hu, L. F., Bian, J. M., ... He, X. P. (2018). Effects of amylopectin structure on gelatinization characteristics of rice starch. Journal of

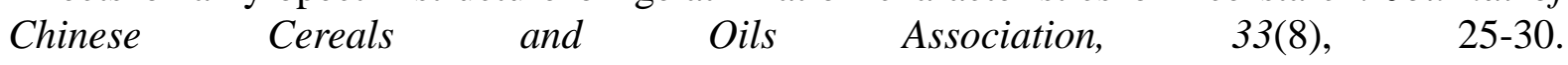
https://doi.org/10.3969/j.issn.1003-0174.2018.08.005

Zhou, L. H., Liu, Q. Q., Zhang, C. Q., Xu, Y., Tang, S. Z., \& Gu, M. H. (2009). Variation and distribution of seed storage protein content and composition among different rice varieties. Acta Agronomica Sinica, 35(5), 884-891. https://doi.org/10.3724/SP.J.1006.2009.00884

\section{Copyright Disclaimer}

Copyright for this article is retained by the author(s), with first publication rights granted to the journal.

This is an open-access article distributed under the terms and conditions of the Creative Commons Attribution license (http://creativecommons.org/licenses/by/4.0/). 